\title{
Managing pediatric otorhinolaryngology patients in coronavirus disease-19 pandemic - A real challenge to the clinicians
}

\author{
Santosh Kumar Swain ${ }^{1}$, Ishwar Chandra Behera ${ }^{2}$ \\ From 'Professor, Department of Otorhinolaryngology, IMS and SUM Hospital, Siksha "O” Anusandhan University, Bhubaneswar, Odisha, India, \\ ${ }^{2}$ Professor, Department of Community Medicine, IMS and SUM Hospital, Siksha "O” Anusandhan University, Bhubaneswar, Odisha, India
}

\begin{abstract}
The novel coronavirus disease (COVID-19) pandemic is posing unprecedented challenges among the otolaryngologists during managing the pediatric patients. COVID-19 infection is caused by novel coronavirus called severe acute respiratory syndrome coronavirus- 2 . This infection is transmitted primarily through human contact and by droplet route. The pediatric otolaryngologists have a critical role for managing nose, paranasal sinus, ears, oral cavity, pharynx, and larynx, which are important sites for generating aerosols and virus transmission. Asymptomatic pediatric patients have high risk for viral shedding. In COVID-19 pandemic, the surgical procedure by pediatric otolaryngologists should be limited to the emergency condition. The surgical interventions should limit the viral dissemination. This review article provides an overview of common methods to limit the viral transmission to the otolaryngologists and assisting health-care staffs from COVID-19 infections during the management of the pediatric patients.
\end{abstract}

Key words: Coronavirus disease-19 pandemic, Flexible nasopharyngolaryngoscopy, Otorhinolaryngology, Pediatric patients, Pediatric tracheostomy

$\mathrm{S}$ evere acute respiratory syndrome coronavirus-2 (SARS-CoV-2) is the causative agent for the outbreak of the coronavirus disease (COVID-19), started in Wuhan, China, since late December 2019 [1]. SARS-CoV-2 was earlier known as the 2019 novel coronavirus (2019-nCoV), an enveloped singlestranded RNA virus [1]. The otolaryngologists have an important role as health-care providers for examining the patients with otorhinolaryngological manifestations. There are concerns for a greater number of the asymptomatic pediatric patients infected with COVID-19 [2]. The pediatric patients often present with diseases related to the upper airway such as sinonasal infections, tonsillitis, pharyngitis, nasal foreign body, airway foreign body, otitis media, and adenoid infections. There are disproportionately a high number of clinicians, infected with COVID-19 during their patient care specifically the pediatric age group [3]. This infection spreads mainly through the respiratory airway by droplets, secretions, and direct contact [4].

Examination and procedure in otolaryngology patients involve upper aerodigestive areas which are high risk for viral transmission, making the pediatric otolaryngologist the most vulnerable healthcare professionals. At present, the risk of the viral transmission from the asymptomatic pediatric patients with COVID-19 to the

\section{Access this article online}

Received - 31 July 2020

Initial Review - 15 August 2020

Accepted - 28 August 2020

DOI: $10.32677 / \mathrm{IJCH} .2020 . v 07.109 .001$ health care workers is often difficult to assess on the basis of the clinical evaluation. The asymptomatic pediatric patients present high chance of the viral shedding during the clinical examination or any surgical procedure on the nose, paranasal sinuses, oral cavity, and laryngopharyngeal region and transmit these infections to the clinicians and assisting team members [5]. The COVID-19 pandemic requires careful assessment of the pediatric patients specifically before any otorhinolaryngological intervention such as laryngotracheobronchial airway, sinonasal tract, oral cavity, and otological procedures.

\section{METHODS OF THE LITERATURE SEARCH}

Research articles regarding managing pediatric otorhinolaryngology patients in COVID-19 pandemic were searched through multiple approaches. First, we conducted an online search of the PubMed, Scopus, Google Scholar, and Medline databases with the word pediatric otorhinolaryngology patients, COVID-19 pandemic, flexible nasopharyngolaryngoscopy in pediatric patients, pediatric tracheostomy, pediatric endoscopic sinus surgery, pediatric mastoid surgery, and hearing screening of the pediatric patients in current COVID-19 pandemic. A search strategy using Preferred Reporting Items for Systematic Reviews and Meta-Analysis guidelines was developed. Randomized

Correspondence to: Santosh Kumar Swain, Department of Otorhinolaryngology, IMS and SUM Hospital, Siksha "O" Anusandhan University, Bhubaneswar, Odisha, India. E-mail: santoshvoltaire@yahoo.co.in

(C) 2020 Creative Commons Attribution-NonCommercial 4.0 International License (CC BY-NC-ND 4.0). 
controlled studies, observational studies, comparative studies, case series, and case reports were evaluated for the eligibility.

This paper focuses only on the pediatric patients with otorhinolaryngology complaints and their management in COVID-19 pandemic. The search articles with adult and elderly patients with their otorhinolaryngological manifestations with their management are excluded. Review articles with no primary research data were also excluded. The abstracts of the published article were identified by this search method and other articles were identified manually from the citations. This review article reviews the COVID-19 virus, epidemiology, history, and preventions of the viral transmission during managing the pediatric otorhinolaryngology patients in COVID-19 pandemic. This review article presents a baseline from where further prospective trials can be designed and help as a spur for further research in this clinical entity where not many studies are done.

\section{COVID-19 Virus}

The etiologic agent for COVID-19 infection was identified as a novel coronavirus, called as SARS-CoV-2, and this disease was called COVID-19 by the World Health Organization (WHO) [6]. This virus was formerly known as 2019-nCoV, positive-sense, single-stranded RNA virus with diameter of $60-140 \mathrm{~nm}$ [6]. It is a new variety of the coronavirus which belongs to the genus of beta coronavirus [7]. By far, 2019-nCoV is the seventh member of the coronavirus family which can infect human beings. The incubation period of COVID-19 ranges from 1 to 14 days with a median of 5-6 days. As per the recent study, the incubation period may extend up to 24 days [8]. A longer incubation has implication in quarantine policies and prevention of the spread of the disease. This virus is primarily transmitted through respiratory droplets but also found in blood and stool, thus raising doubts regarding mode of transmission [9].

\section{History}

The initial patient of pneumonia due to SARS-CoV-2 manifesting COVID-19 was found in Wuhan, Hubei Province, China in December 2019 [4]. This progressed to widespread infections with human transmission and led to pandemic with disastrous manifestations all over the world. The aerosol transmission of the virus was observed during the COVID-19 crisis, specifically after endoscopic hypophysectomy at Wuhan, where the novel coronavirus infected 14 staff members of the surgical team [10]. The coronaviruses were detected in the upper airway infection way back in 1998 [11]. However, there is limited knowledge in medical professionals about the behavior of the new SARS-CoV-2 in the anatomical area of the ear, nose, and throat.

\section{Epidemiology}

The WHO has declared COVID-19 as pandemic disease on March 11, 2020, and COVID-19 had spread to around 199 countries by March 26, 2020, with more than 462,680 positive cases and approximately 20,834 deaths [12]. The pandemic of COVID-19 is affecting the clinical practice for routine patient care. It is also affecting the day-to-day pediatric otorhinolaryngology practice and specifically surgical intervention of the routing and emergency diseases impacting the quality of life. Over a week, the COVID-19 spread to Asian countries, then to Europe and the United States, and finally globally with a rapid doubling time (6.4 days) [13]. It was declared as a public health emergency by the WHO on January 20, 2020 [13].

A majority $(81 \%)$ of the patients is asymptomatic or present only mild symptoms, whereas approximately $15 \%$ show severe forms requiring hospitalization [14]. Approximately 3\%-4\% of the cases require respiratory support in an intensive care unit (ICU). The mortality or death rate is around $0.39 \%-4 \%$ but it depends on the age of the patients and is more in elderly patients older than 70 years [14]. Although the transmission of this virus mainly occurs through symptomatic patients, it has also been documented in asymptomatic persons and those in incubation period, lasting more than 14 days [14]. These asymptomatic individuals are source of occult transmission.

One of the largest global studies showed that only $2 \%$ of the patients were less than 18 years of age [15]. However, the exact incidence of the pediatric COVID-19 may be more as $4.4 \%-$ $28 \%$ are asymptomatic, whereas additional $51 \%$ show severe symptoms [16]. At present, data show that approximately $15 \%$ of the pediatric COVID-19-positive cases are asymptomatic, whereas approximately $25 \%$ present with symptoms of upper respiratory tract infection [1].

\section{Pediatric Patient Assessment}

At present, all the pediatric patients coming for otorhinolaryngological consultations are treated as suspected COVID-19 cases until proven otherwise [17]. Asymptomatic or mild symptomatic patients spread COVID-19 in approximately $79 \%$ of the documented cases [18]. Before any otorhinolaryngological procedures, the children should be screened for any clinical presentation favoring or suspecting COVID-19 (Table 1).

Viral shedding starts before the onset of the symptoms. The airways of the infected pediatric patients have high viral load particularly in the nose, nasopharynx, oropharynx, larynx, and trachea [19]. The transmission risk of the COVID-19 infections varies for different pediatric otorhinolaryngological procedures and divided into low risk and high risk (Table 2).

\section{Flexible Nasopharyngolaryngoscopy}

The flexible nasopharyngolaryngoscopy has restricted indications during COVID-19 pandemic as it has a high risk for viral transmission to the health care workers and other surrounding personnel [20]. It should be performed only in critical conditions such as airway obstruction to assess the site of obstructive pathology and performing intervention in compromised airway. When performing such procedure, the otolaryngologists must wear the personal protective equipment (PPE) such as filtering 
Table 1: Clinical screening before otorhinolaryngological procedure in children

\begin{tabular}{ll}
\hline Serial number & High-risk clinical presentations \\
\hline 1 & Travel history to outside state/country \\
2 & Contact with COVID-19-positive patients \\
3 & Fever \\
4 & Influenza-like symptoms \\
5 & Shortness of breath \\
6 & Cough \\
7 & Sore throat \\
8 & Altered taste sensation \\
9 & Altered smell sensation \\
\hline
\end{tabular}

Table 2: Transmission risk in pediatric otorhinolaryngology surgical procedure

\begin{tabular}{ll}
\hline Low-risk non-mucosal surgery & High-risk transmucosal surgery \\
\hline Thyroid surgery & Tonsillectomy \\
Neck dissection & Adenoidectomy \\
Neck abscess drainage & Direct laryngoscopy \\
Parotid surgery & Rigid bronchoscopy \\
Branchial cleft/cyst excision & Endoscopic sinus surgery \\
Foreign body removal from the ear & Middle ear/mastoid surgery \\
Pre-auricular sinus excision & Microlaryngeal surgery \\
& Tongue surgery \\
& Foreign body removal from nose \\
\hline
\end{tabular}

face piece 2 (FFP2) mask, gown, head cap, face shield, and protective goggles. After finishing the procedures, PPE should be thrown into the specially made infected waste basin except the protection goggles which can be decontaminated and reused. The flexible endoscope should be kept separately on the table. If the camera is used, must be surrounded with a protective cover. The flexible nasopharyngolaryngoscopy should be properly sterilized. The surface areas of the examination room should be thoroughly cleaned. The next procedure should be delayed at least by $30 \mathrm{~min}$.

\section{Newborn Hearing Screening}

This procedure should be performed by the audiologists who have no direct contact with COVID-19 patients [21]. The mother of the baby should be asymptomatic. The audiologist performing the test should wear surgical mask and surgical gloves before and after each test. The gloves should be changed after each test. The equipment used for the hearing screening must be decontaminated after every use.

\section{Pre-operative Testing}

Once the surgery is planned for the pediatric patient, pre-operative testing for COVID-19 should be done using nasopharyngeal swab with real-time polymerase chain reaction $48 \mathrm{~h}$ before surgery. The emergency surgical procedures should not be delayed as in stridor, hemorrhage, or severe infections. Since the sensitivity of the computed tomography (CT) scan of the thorax is more than $90 \%$ [22], it can be performed for immediate results. If the pre-operative report is COVID-19 positive, non-emergency surgery should be delayed for at least 14 days (usual duration of the quarantine period). CT scan of the thorax should be routinely performed in case of laryngotracheobronchial foreign body in children [22]. CT scan of the thorax is highly sensitive and specific to confirm the foreign body in the airway and minimize the negative bronchoscopy rates [23]. If the child is clinically unstable or with stridor, he should be shifted to the operating room $(\mathrm{OR})$ with full precautions and PPE.

\section{Precautions in the OR}

The number of the health care workers including the surgeons should be minimal in OR. The surgery should be performed by experienced surgeon in less duration. Everybody in OR should wear protective goggles. The surgeon should use N95 mask, cap, face shield, and gown along with protective goggles. In case of positive case, FFP2 mask should be worn by OR staff. If possible, the surgery should be performed in the negative pressure OR with air purification/filtration system. Surgical techniques producing suspension of the infected tissues should be avoided such as drilling of the mastoid bone, microdebrider for endoscopic sinus surgery, monopolar electrocautery, laser, radiofrequency, coblation, and microdebriders [24].

\section{Anesthesia for Pediatric Otolaryngologic Procedures}

The major challenge for anesthesiologists is to deal with suspected or a confirmed case of COVID-19 pediatric patients. A dedicated OR is required for COVID-19-positive cases. Disposable laryngoscope and video laryngoscope should be encouraged during intubations reducing the transmission of infection. In such cases, high-flow nasal cannula should be avoided. Fiber-optic bronchoscopy-guided intubation should be avoided but can be used in emergency. If extracorporeal membrane oxygenation is available, it is preferable in emergency surgical airway in case of positive, suspected, or unknown COVID-19 patients. There should be systematic checklist and appropriated areas for donning and doffing near to the OR.

Adequate hypotensive anesthesia is helpful to reduce bleeding and minimize the related aerosolization of the blood and irrigation fluids. The anesthetists and the team should wear N95 mask, head caps, face shield, protective goggles, disposable gowns, and gloves during intubation and extubation [25]. Children with pneumonia can be deferred for the surgery. In case of patients of pneumonia with false-negative COVID-19 undergoing surgery under general anesthesia, the mechanical ventilation can worsen the status of the COVID-19 patient [26].

\section{Pediatric Tracheostomy}

Tracheostomy is a high-risk surgical procedure in COVID-19 pandemic, as it generates aerosols easily transmitting the virus. The elective tracheostomy can be delayed until active COVID19 infections have passed with consideration of the current 
guidelines [27]. Non-fenestrated cuffed tracheostomy should be used to minimize the aerosol spread. There should be initial advancement of the endotracheal tube before performing the tracheostomy. Ventilation should be stopped as it helps to produce aerosols [27]. Before inserting the tracheostomy, the cuff should be checked for any leak.

After tracheostomy, the tube changes should be delayed till infectivity of the patient ceases. Clinician should carefully judge the selection of the method of the humidification and a heat moisture exchanger as an alternate to the wet circuit reducing the aerosol generation. The occluded tracheostomy tube may disrupt the circuit at the time of the emergency enhancing aerosol spread. Different case series of tracheotomies were done at the time of COVID-19 pandemic showing techniques and preventing measures (Table 3) [28-30].

\section{Pediatric Airway Surgery}

Microlaryngeal surgery, rigid bronchoscopy, and laryngotracheal reconstruction in pediatric patients are high-risk procedures during the current COVID-19 pandemic and there are enhanced chances of the transmission of the infections to the health care workers because of aerosol generation and prolonged gas flow [27]. Emergency tracheostomy provides a significant risk for virus aerosolization and should be done with extreme caution. Routine direct laryngoscopy, bronchoscopy, or tracheoscopy should be avoided specifically in stable patients without any airway symptoms. If children with airway symptoms are present, surgery may be planned following the COVID-19 testing with the use of appropriate PPE.

\section{Pediatric Endoscopic Sinus Surgery}

Non-emergency sinus or nasal surgery should not be performed at the time of the COVID-19 pandemic. Pediatric patients of sinusitis with orbital cellulitis can be recommended for surgery. The sinonasal pathology threatening the vision or resulting in intracranial complications should be planned for endoscopic sinus surgery $[23,24]$. An external approach can be adopted because of the high viral load in the nasal cavity. In case of the endoscopic sinus surgery, throat pack should be given with caution as the insertion of the throat pack has chance of producing aerosols, however, the secretions of the pharynx may stimulate the coughing during emergency from anesthesia. The nasal bone fracture of the pediatric patient should not be recommended in this current pandemic time unless there is association with nasal septal hematoma [23].

\section{Pediatric Otologic Diseases}

Middle ear cleft mucosa such as the mucosal lining of the mastoid air cells and middle ear is considered as part of the upper respiratory airway in terms of the lining epithelium [31,32]. The middle ear cleft connects the nasopharynx by eustachian tube to the mastoid air cells and antrum by aditus $[33,34]$. Drilling of the mastoid bone can cause clouding of the irrigation and bone dusts, easily contacting facial skin and also inhaled by the surgeon and assisting staff [34]. Children with bilateral otitis media with effusion and hearing loss must be prioritized for tympanostomy tube placement but can be deferred till getting the COVID-19 test report. Mastoidectomy can be deferred if possible and if mastoid exploration is required, adequate PPE must be used by the otolaryngologists and high-speed drill should be avoided.

\section{Mortality}

COVID-19 causes high mortality among adult populations, whereas low mortality is found in pediatric age [15]. The early report regarding mortality rate in China was approximately

Table 3: Different case series of open surgical tracheostomies done at the time of COVID-19 pandemic [28-30]

\begin{tabular}{|c|c|c|c|}
\hline Parameters & Wei et al. [28] & Chee et al. [29] & Tien et al. [30] \\
\hline Hospital & $\begin{array}{l}\text { Queen Mary Hospital, Hong } \\
\text { Kong SAR, China }\end{array}$ & Tan Tock Seng Hospital, Singapore & $\begin{array}{l}\text { Sunnybrook and Women's College } \\
\text { Health Sciences Centre, Toronto, } \\
\text { Ontario, Canada }\end{array}$ \\
\hline $\begin{array}{l}\text { Number of } \\
\text { tracheostomies done }\end{array}$ & 3 & 15 & 3 \\
\hline $\begin{array}{l}\text { Barrier precautions } \\
\text { at time of surgery }\end{array}$ & $\begin{array}{l}\text { Standard PPE, shoe covers, face } \\
\text { shield, eye goggles }\end{array}$ & $\begin{array}{l}\text { Standard PPE, shoe covers, powered air- } \\
\text { purifying respirator system }\end{array}$ & $\begin{array}{l}\text { Standard PPE, Stryker T4 protection } \\
\text { system }\end{array}$ \\
\hline Setting & $\begin{array}{l}\text { Negative pressure room inside } \\
\text { ICU or operation room }\end{array}$ & Negative pressure room inside ICU & Negative pressure room inside ICU \\
\hline $\begin{array}{l}\text { Intraoperative } \\
\text { steps to minimize } \\
\text { aerosolization }\end{array}$ & $\begin{array}{l}\text { Complete paralysis of patient, } \\
\text { mechanical ventilation stopped } \\
\text { before tracheostomy, no suction } \\
\text { used during procedure, diathermy } \\
\text { avoided as much possible }\end{array}$ & $\begin{array}{l}\text { Complete paralysis of the patient, } \\
\text { mechanical ventilation stopped before } \\
\text { tracheostomy, limited suction used during } \\
\text { procedure, no specific avoidance of } \\
\text { diathermy other than during tracheostomy }\end{array}$ & $\begin{array}{l}\text { Complete paralysis of the patient, } \\
\text { mechanical ventilation stopped before } \\
\text { tracheostomy, no suction used once } \\
\text { trachea opened, diathermy avoided as } \\
\text { much as possible }\end{array}$ \\
\hline Surgical team & $\begin{array}{l}\text { Single surgeon, one intensive care } \\
\text { specialist, one standby medical or } \\
\text { nursing staff }\end{array}$ & $\begin{array}{l}\text { An experienced surgeon, an experienced } \\
\text { anesthesiologist, one scrub nurse and one } \\
\text { surgical assistant }\end{array}$ & $\begin{array}{l}\text { Senior attending trauma surgeon, most } \\
\text { senior surgical staff member available, } \\
\text { attending ICU anesthetist and no } \\
\text { circulating nurse or scrub nurse. }\end{array}$ \\
\hline
\end{tabular}


$2.3 \%$, whereas global mortality rate is approximately $6 \%[15]$. The mortality rate among the critical COVID-19 patients is approximately $50 \%$ [15].

\section{PPE for Pediatric Emergency}

The PPE includes FFP3 masks or powered air-purifying respirator, long sleeved gown, surgical gloves, disposable eye protectors, and face shields. Only with appropriate PPE, examinations of the oral cavity, nasal cavity, and larynx should be undertaken. The risk of the viral transmissions will be minimized by use of the N95 mask and adequate PPE [35]. The strategies for preventing the transmission of the virus include adequate PPE use with head cap, face shield, face, and neck covering of the drapes limiting the spread of the infection particles generated by the high-speed drilling [36]. FFP3 masks with protective goggles or face shield or FFP2 in case of limited resource can be used by the surgical team during the mastoid surgery.

\section{CONCLUSION}

Effective management of the pediatric otolaryngology patients needs careful considerations of the health care workers and otolaryngologists considering their safety. The preventive interventions are increased testing of COVID-19 among children, using full PPE during any interventions, experienced otolaryngologist performing the procedures to minimize the workforce, and postponement of elective surgeries and clinic visits.

\section{REFERENCES}

1. Lu X, Zhang L, Du H, Zhang J, Li YY, Qu J, et al. SARS-CoV-2 infection in children. N Engl J Med 2020;382:1663-5.

2. General Office of the National Health Commission. The Diagnosis and Treatment Protocol for COVID-19. $6^{\text {th }}$ ed. China: National Health Commission; 2020.

3. Lu D, Wang H, Yu R, Yang H, Zhao Y. Integrated infection control strategy to minimize nosocomial infection of coronavirus disease 2019 among ENT healthcare workers. J Hosp Infect 2020;104:454-55.

4. Li Q, Guan X, Wu P, Wang X, Zhou L, Tong Y, et al. Early transmission dynamics in Wuhan, China, of novel coronavirus-infected pneumonia. N Engl J Med 2020;382:1199-207.

5. Frauenfelder C, Butler C, Hartley B, Cochrane L, Jephson C, Nash R, et al. Practical insights for paediatric otolaryngology surgical cases and performing microlaryngobronchoscopy during the COVID-19 pandemic. Int J Pediatr Otorhinolaryngol 2020;134:110030.

6. Zhu N, Zhang D, Wang W, Li X, Yang B, Song J, et al. A novel coronavirus from patients with pneumonia in China, 2019. N Engl J Med 2020;382:727-33.

7. Guan WJ, Ni ZY, Hu Y, Liang WH, Ou CQ, He JX, et al. Clinical characteristics of coronavirus disease 2019 in China. N Engl J Med 2020;382:1708-20.

8. Bai Y, Yao L, Wei T, Tian F, Jin DY, Chen L, et al. Presumed asymptomatic carrier transmission of COVID-19. JAMA 2020;323:1406-7.

9. Zhang W, Du RH, Li B, Zheng XS, Yang XL, Hu B, et al. Molecular and serological investigation of 2019-nCoV infected patients: Implication of multiple shedding routes. Emerg Microbes Infect 2020;9:386-9.

10. China News Weekly. Restore the Infection Path of "Super Communicator"
Wuhan Doctor: The Epidemic just Started. Article in Chinese (Simplified). Available from: http://www.View.inews.qq.com/a/20 200125 A 07TT200 $?$ uid $=\&$ devid=BDFE70CD -5 BF 1-4702-91B $7-$ 329F20A6E839\&qimei=bdfe70cd5bf1-4702-91b7-329f20a6e839. [Last accessed on $2020 \mathrm{Apr} 20]$.

11. Pitkäranta A, Jero J, Arruda E, Virolainen A, Hayden FG. Polymerase chain reaction-based detection of rhinovirus, respiratory syncytial virus, and coronavirus in otitis media with effusion. J Pediatr 1998;133:390-4.

12. World Health Organization. Coronavirus Disease 2019 (COVID-19): Situation Report-66. Geneva: World Health Organization; 2019. Available from: https://www.who.int/emergencies/diseases/novel-coronavirus-2019/ situation-reports. [Last accessed on 2020 Mar 26].

13. Chan KW, Wong VT, Tang SC. COVID-19: An update on the epidemiological, clinical, preventive and therapeutic evidence and guidelines of integrative Chinese-Western medicine for the management of 2019 novel coronavirus disease. Am J Chin Med 2020;48:737-62.

14. Wu Z, McGoogan JM. Characteristics of and important lessons from the coronavirus disease 2019 (COVID-19) outbreak in China: Summary of a report of 72314 cases from the Chinese center for disease control and prevention. JAMA 2020;323:1239-42.

15. Dong Y, Mo X, Hu Y, Qi X, Jiang F, Jiang Z, et al. Epidemiological characteristics of 2143 pediatric patients with 2019 coronavirus disease in China. Pediatrics 2020;145:e20200702.

16. Jessop ZM, Dobbs TD, Ali SR, Combellack E, Clancy R, Ibrahim N, et al. Personal protective equipment (PPE) for surgeons during COVID-19 pandemic: A systematic review of availability, usage, and rationing. Br J Surg 2020;107:1262-80.

17. Fang H, Wang L, Yang Y. Human Mobility Restrictions and the Spread of the Novel Coronavirus (2019-ncov) in China. Cambridge, MA: National Bureau of Economic Research; 2020.

18. Zou L, Ruan F, Huang M, Liang L, Huang H, Hong Z, et al. SARS-CoV-2 viral load in upper respiratory specimens of infected patients. N Engl J Med 2020;382:1177-9.

19. Chang D, Mo G, Yuan X, Tao Y, Peng X, Wang FS, et al. Time kinetics of viral clearance and resolution of symptoms in novel coronavirus infection. Am J Respir Crit Care Med 2020;201:1150-2.

20. Kam KQ, Yung CF, Cui L, Thoon KC. A well infant with coronavirus disease 2019 with high viral load. Clin Infect Dis 2020;71:847-9.

21. Pitiot V, Grall M, Ploin D, Truy E, Khalfallah SA. The use of CT-scan in foreign body aspiration in children: A 6 years' experience. Int J Pediatr Otorhinolaryngol 2017;102:169-73.

22. Ahmed OG, Guillerman RP, Giannoni CM. Protocol incorporating airway CT decreases negative bronchoscopy rates for suspected foreign bodies in pediatric patients. Int J Pediatr Otorhinolaryngol 2018;109:133-7.

23. Soma M, Jacobson I, Brewer J, Blondin A, Davidson G, Singham S. Operative team checklist for aerosol generating procedures to minimise exposure of healthcare workers to SARS-CoV-2. Int J Pediatr Otorhinolaryngol 2020;134:110075.

24. Wong J, Goh QY, Tan Z, Lie SA, Tay YC, Ng SY, et al. Preparing for a COVID19 pandemic: A review of operating room outbreak response measures in a large tertiary hospital in Singapore. Can J Anaesth 2020;67:732-45.

25. Jacob T, Walker A, Mantelakis A, Gibbins N, Keane O. A framework for open tracheostomy in COVID-19 patients. Clin Otolaryngol 2020;45:649-51.

26. Malhotra N, Joshi M, Datta R, Bajwa SJ, Mehdiratta L. Indian society of anaesthesiologists (ISA national) advisory and position statement regarding COVID-19. Indian J Anaesth 2020;64:259-63.

27. Swain SK, Das S, Padhy RN. Performing tracheostomy in intensive care unit-a challenge during COVID-19 pandemic. Siriraj Med J 2020;72:436-42.

28. Wei WI, Tuen HH, Ng RW, Lam LK. Safe tracheostomy for patients with severe acute respiratory syndrome. Laryngoscope 2003;113:1777-9.

29. Chee VW, Khoo ML, Lee SF, Lai YC, Chin NM. Infection control measures for operative procedures in severe acute respiratory syndrome-related patients. Anesthesiology 2004;100:1394-8.

30. Tien HC, Chughtai T, Jogeklar A, Cooper AB, Brenneman F. Elective and emergency surgery in patients with severe acute respiratory syndrome (SARS). Can J Surg 2005;48:71-4.

31. Swain SK, Samal R, Pani SK. Effect of smoking on outcome of tympanoplasty. Indian J Otol 2011;17:120-2.

32. Topsakal V, Van Rompaey V, Kuhweide R, Garin P, Barbara M, Li Y, et al. 
Prioritizing otological surgery during the COVID-19 pandemic. B-ENT 2020;16:55-8.

33. Swain SK, Nahak B, Mohanty JN. Pediatric tympanoplasty: Our experiences in a tertiary care teaching hospital of Eastern India. Med J DY Patil Vidyapeeth 2020;13:229-34.

34. Swain SK, Pradhan C, Mohanty S, Sahu MC. Comparative study between selective nerve blocks and the intravenous opioids in mastoid surgery. Egypt J Ear Nose Throat Allied Sci 2017;18:121-5.

35. World Health Organization. Rational Use of Personal Protective Equipment (PPE) for Corona Virus Disease (COVID-19): Interim Guidance. Geneva: World Health Organization; 2020.
36. Singhal T. A review of coronavirus disease-2019 (COVID-19). Indian J Pediatr 2020;87:281-6.

Funding: None; Conflicts of Interest: None Stated.

How to cite this article: Swain SK, Behera IC. Managing pediatric otorhinolaryngology patients in coronavirus disease-19 pandemic - A real challenge to the clinicians. Indian J Child Health. 2020; 7(9):357-362. 